\title{
Effect modifiers of lung function and daily air pollutant variability in a panel of schoolchildren
}

\author{
Graciela Mentz, ${ }^{1}$ Thomas G Robins, ${ }^{1}$ Stuart Batterman, ${ }^{1}$ Rajen N Naidoo (i) ${ }^{2}$
}

'University Michigan, Ann Arbor,

Michigan, USA

${ }^{2}$ Occupational and

Environmental Health, University of KwaZulu-Natal, Durban,

South Africa

\section{Correspondence to}

Professor Rajen N Naidoo,

Occupational and Environmental Health, University of KwaZulu-

Natal, Durban 4041, South

Africa; naidoon@ukzn.ac.za

Received 22 December 2017

Revised 19 August 2019

Accepted 20 August 2019

Published Online First

18 September 2019

\section{ABSTRACT}

Background Acute pollutant-related lung function

changes among children varies across pollutants and lag periods. We examined whether short-term air pollutant

fluctuations were related to daily lung function among a panel of children and whether these effects are modified by airway hyperresponsiveness, location and asthma severity.

Methods Students from randomly selected grade 4 classrooms at seven primary schools in Durban, participated, together with asthmatic children from grades 3-6 $(n=423)$. The schools were from high pollutant exposed communities (south) and compared with schools from communities with lower levels of pollution (north), with similar socioeconomic profiles. Interviews, spirometry and methacholine challenge testing were conducted. Bihourly lung function measurements were performed over a 3-week period in four phases. During all schooldays, students blew into their personal digital monitors every 1.5-2 hours. Nitrogen dioxide $\left(\mathrm{NO}_{2}\right)$, nitrogen oxide (NO), sulphur dioxide and particulate matter $\left(<10 \mu \mathrm{m}\right.$ diameter) $\left(\mathrm{PM}_{10}\right)$ were measured at each school. Generalised estimating equations assessed lag effects, using single-pollutant (single or distributed lags) models.

Results FEV declines ranged from 13 to $18 \mathrm{~mL}$ per unit increase in IQR for $\mathrm{NO}$ and $14-23 \mathrm{~mL}$ for $\mathrm{NO}_{2}$. Among the 5 -day average models, a $20 \mathrm{~mL}$ and $30 \mathrm{~mL}$ greater drop in FEV, per IQR for $\mathrm{NO}_{2}$ and $\mathrm{NO}$, respectively, among those with airway hyperresponsiveness compared with those without. Effects were seen among those with normal airways.

Conclusions This first panel study in sub-Saharan Africa, showed significant declines in lung function, in response to $\mathrm{NO}$ and $\mathrm{NO}_{2}$ with effects modified by airway hyperresponsiveness or persistent asthma.

\section{INTRODUCTION}

Evidence for the association of ambient air pollutants with adverse respiratory health among children is convincing ${ }^{1}$ and includes linkages between asthma incidence and prevalence, emergency room visits and school absences with exposure to particulate matter $(\mathrm{PM})$, ozone $\left(\mathrm{O}_{3}\right)$, oxides of nitrogen $\left(\mathrm{NO}_{\mathrm{x}}\right)$ and sulphur dioxide $\left(\mathrm{SO}_{2}\right){ }^{23}$ These findings are particularly evident among vulnerable subpopulations, including asthmatic children, but the effects are less emphatic among children without asthma. While panel studies of asthmatic children have associated acute symptoms with fluctuations in air pollution levels, more objective tests of airway function, particularly within samples that include both

\section{Key messages}

What is the key question?

- Does exposure to ambient pollutants result in acute changes in lung function among asthmatic and non-asthmatic schoolchildren, and is this modified by airway hyperresponsiveness?

What is the bottom line?

- Short-term fluctuations in oxides of nitrogen are associated with lung function changes in a dose-response manner, and these effects are modified by airway responsiveness, asthma status and location.

Why read on?

- This is the first sub-Saharan study of a panel of schoolchildren, selected from communities with relatively high levels of pollution and compared with children without such exposures, which not only provides evidence of pollutant-related changes in acute lung function, but that these effects are modified by important factors and are present in those without persistent asthma.

asthmatic and non-asthmatic children, have yielded variable results. ${ }^{45}$

Panel studies offer advantages over cross-sectional studies through the repeated measures design, allowing participants to serve as their own controls. In addition, panel studies with repeated measures over short time frames provide an opportunity of investigating lagged effects of exposure. Lung function measures may be a more sensitive indicator of pollutant-related impacts on respiratory health, than reported symptoms, medication usage or emergency department visits. ${ }^{6-8}$

Asthmatic children are the population of choice in panel studies, as a vulnerable subpopulation within whom effects are most pronounced, sometimes at levels below international standards. ${ }^{9}$ The review by Li et al identified the wide range of findings for declines in peak expiratory flow (PEF) across the different studies for the various pollutants and across different lags of exposure. ${ }^{4}$ In a meta-analysis of 22 studies, effects varied across particle size, ranging from $-12 \mathrm{~mL} / \mathrm{min}$ per $\mu \mathrm{g} / \mathrm{m}^{3}$ increase in $\mathrm{PM}_{10}$ to $-63 \mathrm{~mL} / \mathrm{min}$ per $\mu \mathrm{g} / \mathrm{m}^{3}$ increase in $\mathrm{PM}_{2.5}{ }^{10}$ In a 2010 meta-analysis of 34 panel studies, a $10 \mu \mathrm{g} /$ $\mathrm{m}^{3}$ increase in $\mathrm{PM}_{10}$ was associated with a $82 \mathrm{~mL} /$ min decrease of PEF. ${ }^{5}$ Findings for $\mathrm{NO}_{2}$ vary: the earlier meta-analysis showed $180 \mathrm{~mL} / \mathrm{min}$ decline 
in PEF per $\mu \mathrm{g} / \mathrm{m}^{3}$ increase in $\mathrm{NO}_{2}$, while the subsequent report found no $\mathrm{NO}_{2}$ related effect. Other panel studies have reported effects with $\mathrm{NO}_{2}$ of $28 \mathrm{~mL} / \mathrm{min}$ in PEF for a $10 \mu \mathrm{g} / \mathrm{m}^{3}$ increase in pollutant. ${ }^{11}$ Responses to $\mathrm{SO}_{2}$ varied across studies and generally estimates with wide CIs, including the null effect. ${ }^{4} 7910$

Studies using population-based samples that include asthmatics and non-asthmatics fail to exhibit strong exposure-response relationships. ${ }^{1} 9$ Population-based studies typically define asthma cases using reported physician diagnoses. ${ }^{10}$ Comparison of effects between those with and without disease in studies without objective measures may be biased, particularly within populations in which healthcare access is restricted. There have been limited studies which have employed tests of airway hyperresponsiveness (AHR). The latter provides a more sensitive marker of airway compromise and therefore likely to explain more precisely exposure-outcome relationships.

This paper examines whether short-term fluctuations in air pollutant concentrations are related to changes in daily lung function parameters among a panel of 423 children in Durban, South Africa, and whether these effects are modified by AHR, location and asthmatic status.

\section{METHODS}

\section{Background of study area}

Durban is Africa's busiest port and the primary route for imported crude oil and exported refined petroleum and petrochemical products. The south of the city is highly industrialised with elevated levels of $\mathrm{SO}_{2}, \mathrm{NO}_{x}, \mathrm{PM}$, carbon monoxide (CO), hydrogen sulphide $\left(\mathrm{H}_{2} \mathrm{~S}\right)$ and other pollutants. ${ }^{12}$

\section{Selection of communities and schools}

Four communities in the industrialised south and three communities in north Durban were selected on the basis of contrasts in emission sources and expected pollutant levels, but with similar socioeconomic profiles. The south communities are located in residential areas in close proximity to industrial emissions, while this is not the case for the north communities. In our sample, approximately $20 \%$ of participants had incomes below the 'upper-bound poverty line' of US\$76 per person per month ${ }^{13}$ A primary school in each of the seven communities was selected (figure 1) based on their proximity to sources of pollutant exposure, geographical location and numbers of children bussed in from outside communities. Only schools where bussing of students from surrounding communities was minimal $(<15 \%)$ were eligible to ensure that exposure measurements at the schools were reasonably representative of residential exposures of the study sample. One school was randomly chosen from each community. None was selected on the basis of the health status of children at the school. ${ }^{14}$

\section{Student recruitment}

In each school, one or two fourth grade classes were randomly selected. To ensure statistical power to investigate the relationship between persistent asthma and exposure, additional pupils with known or probable persistent asthma were identified from grades 3-6 using a previously validated screening instrument. ${ }^{15}$ 'Known asthma' was based on the report of having been diagnosed as such by a doctor, while 'probable persistent asthma' was based on positive responses to daytime symptoms of persistent wheezing, persistent coughing, chest tightness or shortness of breath more than two times per week (during and outside exercise), sleep disturbances due to wheezing, coughing, chest tightness or shortness of breath more than twice per month or daily

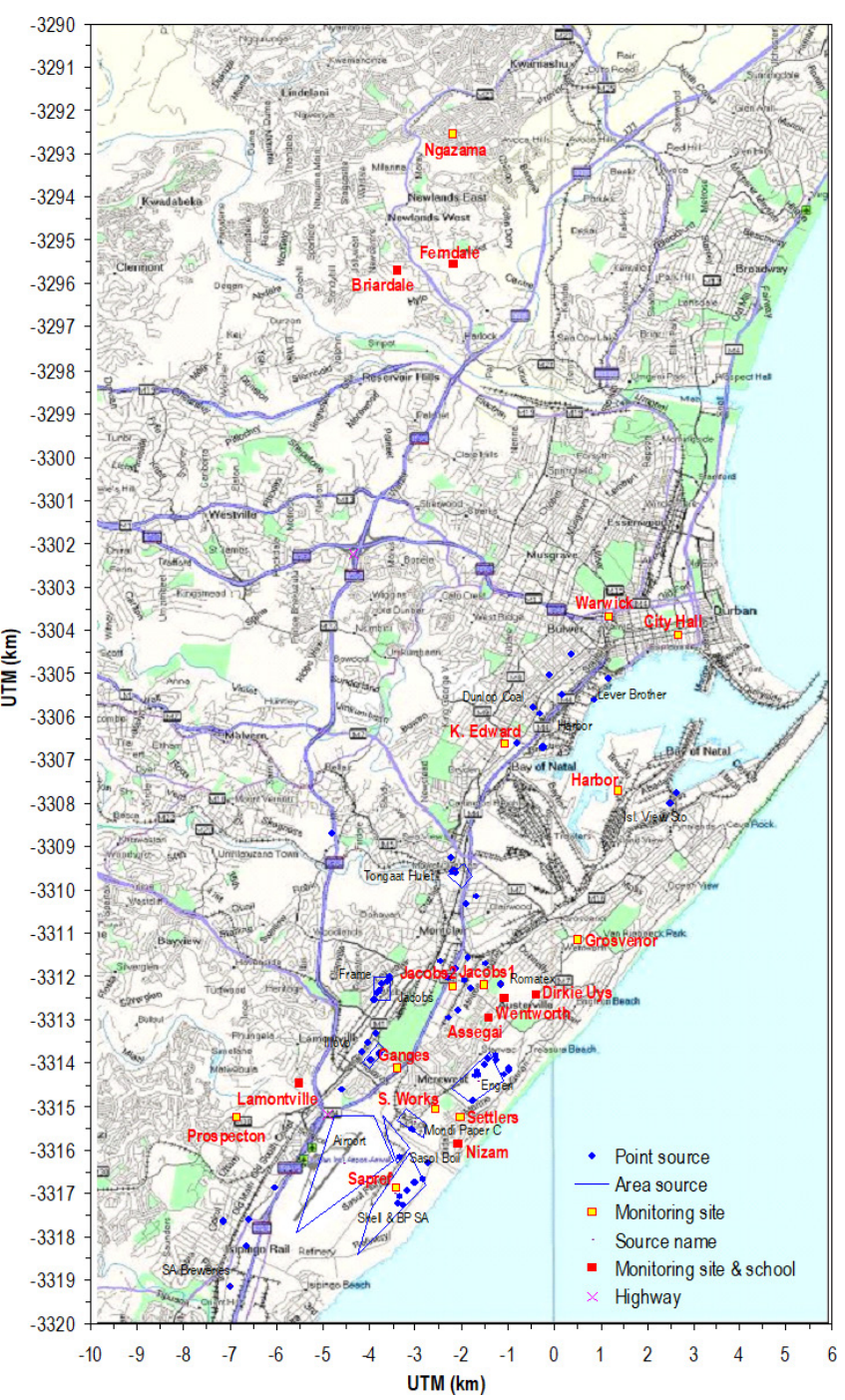

Figure 1 Map of the city of Durban, showing the location of the participating schools, additional monitoring sites and selected point sources (modified from Mentz et $a^{20}$ ).

use of doctor prescribed medication (National Asthma Education and Prevention Program (NAEPP) ${ }^{16}$ and online supplementary material 1). A total of 423 students participated in the study. Of the 366 children from the randomly selected classrooms, $342(93.2 \%)$ participated, with $87.1 \%(n=81)$ of the known or probable persistent asthmatics participating. Written informed consent for the voluntary participation of the children was obtained from their parents or guardians.

\section{Student and caregiver interviews}

Validated questionnaires ${ }^{14}$ were interviewer administered at school to the participating children, and at home to their caregivers, in their preferred language (English, Afrikaans and isiZulu, the latter two being local South African languages). The caregiver responses on child respiratory symptoms were used to determine moderate to severe persistent, mild persistent, mild intermittent or no asthma, using the approach described above in the screening process. ${ }^{16}$

\section{Allergy status assessment}

Skin-prick testing for allergic sensitisation was performed on each participant. Antigens tested included mixed cockroach, 
mixed dust mite, mould mix (Aspergillus, Cladosporium and Penicillium), cat, dog, mouse, rat and mixed grasses, plus histamine as a positive control and saline as a negative control. Atopy positivity was defined as a positive skin prick test to any of the eight common allergens tested.

\section{Collection of pulmonary function data}

The AirWatch (iMetrikus, Carlsbad, California, USA) monitor was used to monitor the fluctuations in PEF and $\mathrm{FEV}_{1}$. Children completed the AirWatch-based pulmonary testing over a 3 -week period in each of four data collection phases, timed to best capture seasonal variation, within the constraints of school holidays and school activities (phase 1: 1-18 June; phase 2: 23 August-10 September; phase 3: 25 October-12 November and phase 4: 7-21 February) while in class, four times per day. These manoeuvres were done following intensive training and performed under supervision by the research team. The assessments were done simultaneously in all classrooms in all schools. Participants were retrained at the beginning of each of the four 3 -week data collection phases. For each participant, a possible 240 lung function data points were available (four times per day, five schooldays per week, 3 weeks per cycle over four phases), with a total of 101520 .

Formal spirometry was conducted by experienced respiratory technicians according to American Thoracic Society (ATS) guidelines. ${ }^{17}$ For these technician-derived measurements, participants were advised to abstain from bronchodilators in the 24 hours preceding testing. Children with baseline obstructive patterns were repeat tested after bronchodilator administration. An abbreviated methacholine challenge testing (MCT) protocol was used for those without obstructive patterns. ${ }^{18}$ Results of the MCT were classified based on $\mathrm{PC}_{20}$ (dose of methacholine causing a $20 \%$ fall in baseline $\mathrm{FEV}_{1}$ ) as follows: marked AHR: $\mathrm{PC}_{20} \leq 4 \mathrm{mg} / \mathrm{mL}$; probable AHR: $4 \leq \mathrm{PC}_{20} \leq 8 \mathrm{mg} / \mathrm{mL}$; possible AHR: $8<\mathrm{PC}_{20} \leq 16 \mathrm{mg} / \mathrm{mL}$; none: $\mathrm{PC}_{20}>16 \mathrm{mg} / \mathrm{mL}$. The higher of the baseline values and the post-bronchodilator (if administered to that particular child either during standard spirometry and/or methacholine challenge testing) values were taken as the child's 'personal best'.

The technician-derived baseline spirometry measures were used to screen for spurious results from the in-class manoeuvres. Only those manoeuvres with $\mathrm{FEV}_{1}$ within $30-120 \%$ of that child's personal best were considered valid. The highest PEF and $\mathrm{FEV}_{1}$ from the valid manoeuvres from each session were analysed. Only the findings of the $\mathrm{FEV}_{1}$ are presented here.

\section{Air quality monitoring}

Air quality instrumentation deployed at each school provided continuous measurements of $\mathrm{CO}, \mathrm{SO}_{2} \mathrm{NO}_{2}, \mathrm{NO}$ and daily samples of $\mathrm{PM}_{10}$ during the four 3-week sessions of lung function monitoring. The Durban municipality also monitored various pollutants at additional sites, mostly in south Durban ${ }^{19}$ (figure 1). Multiple imputation (MI) was used to address pollutant data missingness. MI was performed for each pollutant and site independently. A Markov Chain Monte Carlo (MCMC) method with multiple chain option was used to permit the determination of hourly averages. A data set containing numerous possible predictor variables was constructed. It included meteorological variables, for example, barometric pressure, daily rain fall, relative humidity, temperature, vertical temperature difference (delta T), wind direction by sector (eight total) and wind speed, as well as pollutant variables at all available sites for the same type of pollutant being imputed, for example, $\mathrm{SO}_{2}$ was imputed using observations at the seven school sites as well as observations at eight other sites. The predictor variable data set was augmented by defining leading and lagging variables ( \pm 1 day). After optimising and evaluating performance, $\mathrm{m}=5$ daily average values were generated for each pollutant and site for use in the health model. ${ }^{20}$

Most of usable exposure $\left(\mathrm{PM}_{10}, \mathrm{SO}_{2}, \mathrm{NO}, \mathrm{NO}_{2}\right)$ had an overall capture rate for valid 24 hours observations between $80 \%$ and $83,4 \%$ of the study period, and missing data were largely attributable to holidays, equipment failures, etc. Although missing data was not larger than $25 \%$, the clustering pattern of the missing data was high, with some sites having less than $70 \%$ of captured data. Thus MI was deemed appropriate.

\section{Statistical analysis}

All pollutant measures were averaged over 24 hours. Daily averages were computed from the complete data set of actual and imputed pollutant data. These daily averages were included in the regression models, assessing lung function (peak flow and $\mathrm{FEV}_{1}$ ) measures obtained from the AirWatch monitors. We assumed a linear relationship between exposure and outcome. The lung function data was collected at four sessions per day, and all four measures were used as the daily repeated measures of outcome.

To adjust for the repeated samples design, generalised estimating equations (GEE) were used to assess the pollution-lung function associations. This approach was driven by our interest in robust estimates of fixed effects of exposures. The model accounted for both clustering of repeated measures within children, and clustering of children within schools/geographic locations.

Simulation studies on the behaviour of the GEEs are asymptotic in the number of clusters (m) (in our case, children), with $\mathrm{m}=200$ probably large enough for approximately symmetric data. In addition, these studies show that the total number of observations $\geq 20 * \mathrm{~m}$, for asymptotics of the mixed models, (multilevel models) work well and will test hypothesis with $80 \%$ power or more. In our case, we have $\mathrm{m}=423$ clusters (or participating children) and a total number of observations of 74260 . Based on previous studies with similar designs, we assumed a mean $\mathrm{FEV}_{1}$ of $1.8(\mathrm{~L})$ for children living in low $\mathrm{PM}_{10}$ exposure areas from previous studies. Thus, based on previous studies of similar longitudinal characteristics, with sample sizes of 300 children, producing pollutant-related effect estimates in lung function from 0.02 to 0.33 , our sample size of 423 children had adequate power to demonstrate the exposure-outcome relationships of interest. ${ }^{21-24}$

Single exposure, single-lag effects (1-5 days), as well as 5 -day averages and unconstrained distributed lags (DLM) were modelled. Covariates used in regression models included child's age, gender, race/ethnicity, school, previous history of respiratory disease, atopy status, primary caregiver's education level and smoking history, annual household income and phase. The regression models are explained further in the online supplementary material. Despite the narrow age range of the selected sample mean age $(10$ years $(\mathrm{SD}=0.5))$, the distribution of gender (58\% girls, $42 \%$ boys) and overall low socioeconomic status of the chosen communities, inclusion of these variables were necessary for matters of sampling design issues. With respect to other measures such as rainfall, temperature and humidity, they are directly and indirectly (through MI procedures) considered in the exposure measures, thus including them in the outcome 
models created multicollinearity issues. In our sensitivity analysis, some of the models that included these variables did not converge.

Both single and multiple pollutant models were assessed. Owing to concerns over multicollinearity among pollutants, single pollutant models are presented here.

The general model we considered for this analysis can be written as:

$\mathrm{FEV}_{1}=\beta_{0}+\beta_{1} \operatorname{Conc}+\beta_{2} \mathrm{COV}_{1}+\ldots+\beta_{\mathrm{n}} \mathrm{COV}_{\mathrm{n}-2}$

where Conc took the form of each individual lag from 1 to 5 or 5-day average.

The model was modified to test for effect modification of AHR $($ marked or probable $(\mathrm{AHR}+)$ vs possible or none $(\mathrm{AHR}-))$, asthma severity (persistent vs not persistent (ie, either mild intermittent or no asthma)) and location of child's school (north vs south), through the inclusion of an interaction term.

Analyses were performed using Statistical Analyses Software (SAS) V.8.1.

\section{RESULTS}

The mean age of the participating children was $10.5(\mathrm{SD}=0.9)$. A little over half of participants were females, with the majority of children being of African origin. Using the NAEPP categorisation, 19.5\% had persistent asthma and 38.7\% were atopic (table 1).

Of the total sample of 423 students in the sample, participation rates varied across the seven schools. The expected number of observations for the total sample was $101520(423 \times 4$ times per day $\times 15$ days of observation $\times$ four seasons), and of these, we achieved a $73.1 \%$ success rate (74 260 observations). Generally, the major reason for the loss to follow-up was absence of pupils from school during the assessments. Of the data we collected (74 260), the missing pattern was $10 \%$ or less across different covariates.

Pollutant concentrations showed strong contrasts between northern and southern communities (online supplementary material 1). $\mathrm{SO}_{2}$ concentrations in the south were over fourfold, significantly higher $(\mathrm{p}<0.001)$ than levels in the north (mean $($ south $)=8.7 \mathrm{ppb}$ vs mean $($ north $)=1.9 \mathrm{ppb}) . \mathrm{NO}_{\mathrm{x}}$ levels in the south were also significantly higher $(p<0.001)$, reflecting traffic sources. Maximum 24 hours $\mathrm{PM}_{10}$ concentrations at the northern school sites approached or exceeded $150 \mu \mathrm{g} / \mathrm{m}^{3}$. Pollutant concentrations varied across the different data collection phases : $\mathrm{NO}_{2}$ and $\mathrm{NO}$ had the highest levels in the colder months (data collection phases 1 and 2) (approximately 20-25 $\mathrm{ppb}\left(\mathrm{NO}_{2}\right)$ and a peak of $140 \mathrm{ppb}$ for $\left.\mathrm{NO}\right)$ ) and the lowest levels in phases 3 and 4 ((16-17 ppb ( $\left.\mathrm{NO}_{2}\right)$ and NO below $\left.20 \mathrm{ppb}\right)$. $\mathrm{PM}_{10}$ and $\mathrm{SO}_{2}$ showed similar trends across the data collection phases (figure 2). Mean levels over the study period did not exceed WHO benchmarks. ${ }^{25}$

Increased levels of $\mathrm{NO}$ and $\mathrm{NO}_{2}$ were associated with statistically significant decrements in $\mathrm{FEV}_{1}$ for all examined lags (figure 3A, online supplementary table S2), ranging from $13 \mathrm{~mL}$ (95\% CI -23 to $-3 \mathrm{~mL})$ to $18 \mathrm{~mL}(95 \% \mathrm{CI}-28$ to $-7 \mathrm{~mL})$ ) decrease per interquartile increase in $\mathrm{NO}_{2}$ and $14-23 \mathrm{~mL} / \mathrm{min}$ for $\mathrm{NO}$, with $\mathrm{p}$ values ranging from $<0.002$ to 0.011 for $\mathrm{NO}_{2}$ and $<0.001$ for NO. Patterns across the four lag structures of the two pollutants in the pulmonary function outcomes are very similar, with the 5-day average lag showing greater point estimates of decrements, but wider CIs, than the single-day lags.

When assessing for effect modification by AHR, the patterns of the estimates for AHR + and AHR - are similar for both $\mathrm{NO}$ and $\mathrm{NO}_{2}$. Among those with $\mathrm{AHR}+$, greater point estimates of decrements with wider CIs, were seen, compared with
Table 1 Sample characteristics $(n=423)$

\begin{tabular}{|c|c|c|}
\hline Variable name & $\mathrm{N}$ & Statistic \\
\hline \multicolumn{3}{|l|}{ Demographics } \\
\hline Age, mean (SD) & 423 & $10.5(0.9)$ \\
\hline \multicolumn{3}{|l|}{ Gender (\%) } \\
\hline Female & 238 & 57.2 \\
\hline \multicolumn{3}{|l|}{ Race (\%) } \\
\hline African & 159 & 44.2 \\
\hline Coloured* $^{*}$ & 82 & 22.8 \\
\hline Indian & 99 & 27.5 \\
\hline White & 20 & 5.6 \\
\hline \multicolumn{3}{|l|}{ Caregiver education (\%) } \\
\hline Less than high school & 129 & 39 \\
\hline High school graduate & 144 & 43.5 \\
\hline More than high school & 56 & 16.9 \\
\hline Refused & 2 & \\
\hline \multicolumn{3}{|c|}{ Total annual household income (\%) } \\
\hline$<$ US\$1500 & 57 & 28.2 \\
\hline US\$1501-4500 & 54 & 26.8 \\
\hline US\$4501-8000 & 43 & 21.3 \\
\hline US\$8001 and above & 48 & 23.7 \\
\hline
\end{tabular}

Child's health outcomes

Asthma severity (\%)

$\begin{array}{lll}\text { Moderate to severe } & 27 & 7.2\end{array}$

$\begin{array}{lll}\text { Mild persistent } & 46 & 12.3 \\ \text { Mild Intermittent } & 74 & 19.7 \\ \text { None } & 228 & 60.8\end{array}$

Airway hyperresponsiveness (\%)

\begin{tabular}{lcl}
\multicolumn{1}{|c}{ Marked } & 29 & 9.6 \\
\hline Probable & 21 & 7 \\
\hline Possible & 31 & 10.3 \\
\hline None & 221 & 73.2 \\
\hline Technician derived FEV (mean (SD)) & 369 & $1.74(0.39)$ \\
\hline Airwatch obtained FEV, (Mean (SD)) & 423 & $1.6(0.5)$ \\
\hline Airwatch obtained peak expiratory flow (mean (SD)) & 423 & $275.2(69.7)$ \\
\hline Atopy,\% yes & 136 & 38.7 \\
\hline Caregiver smokes, \% & 105 & 28.5 \\
\hline Mean number of smokers in household (mean (SD)) & 344 & $0.9(1.0)$ \\
\hline Households with one or more smokers (\%) & 242 & 27.2 \\
\hline
\end{tabular}

*'Coloured' people were defined as those of mixed ethnicity, based on the old racial classification system in South Africa. Although no longer a legal definition, 'race' or ethnicity still substantially predicts socioeconomic status in the country.

AHR - (figure 4A, online supplementary material 1). These wider CIs reflect the small sample size of schoolchildren with $\mathrm{AHR}+(\mathrm{n}=50)$. For those with AHR-, pollutant-related decrements were consistent across most lags, with estimates ranging from $19 \mathrm{~mL}(95 \% \mathrm{CI}-34$ to $-5 ; \mathrm{p}<0.01)$ to $12 \mathrm{~mL}(95 \% \mathrm{CI}-24$ to $-1 ; \mathrm{p}=0.04)$. Among the 5 -day average models, there was a $50 \mathrm{~mL}$ drop in $\mathrm{FEV}_{1}$ per increase in IQR of $\mathrm{NO}_{2}$ among those with AHR + compared with to $30 \mathrm{~mL}$ among those without, and $90 \mathrm{~mL}$ versus $60 \mathrm{~mL}$ drop per IQR increase for NO among those with and without, respectively. This pattern was replicated for the other lags. 
A

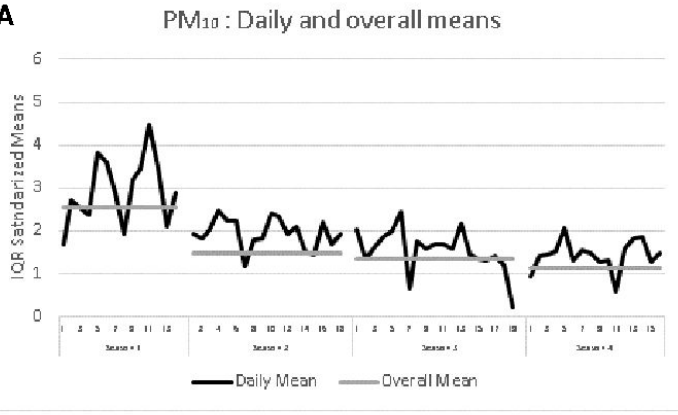

B

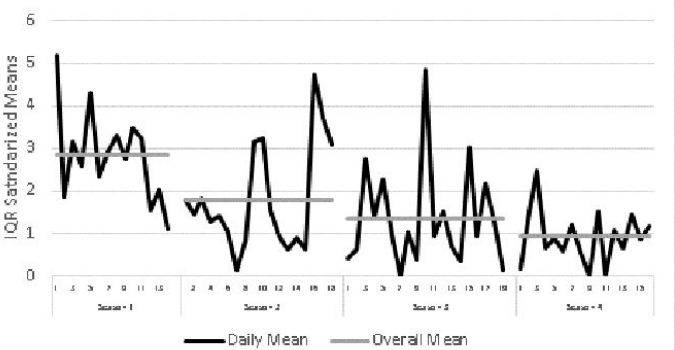

C

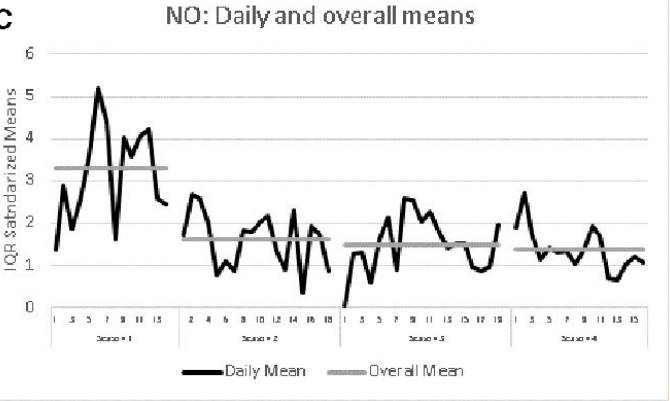

D

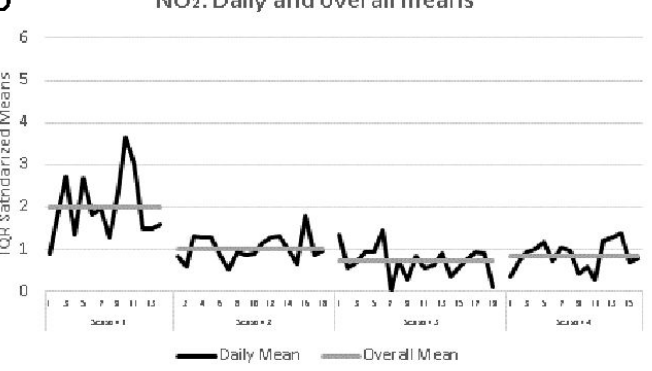

A

FEV,

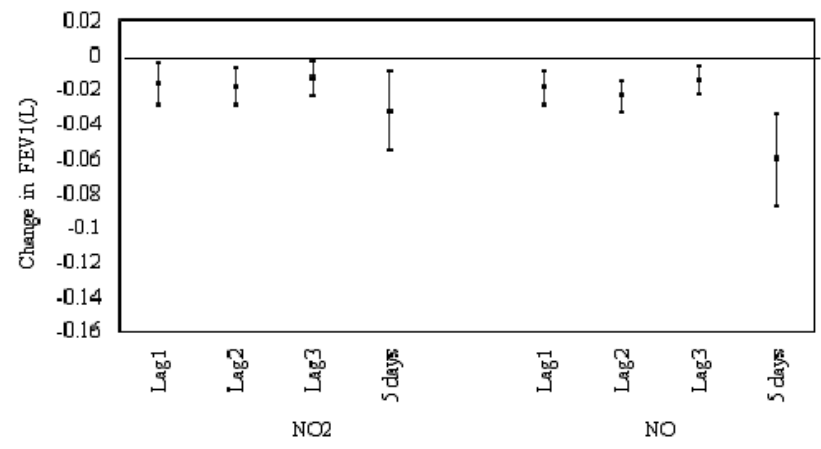

B FEV,

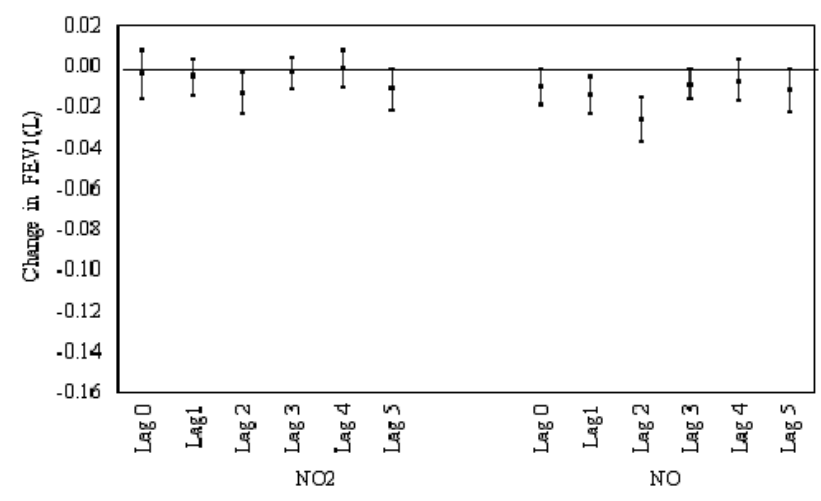

Figure 3 Change in $\mathrm{FEV}_{1}$ and its $95 \% \mathrm{Cl}$ associated with one IQR ${ }^{1}$ increase in ambient levels of nitrogen dioxide $\left(\mathrm{NO}_{2}\right)^{2}$ and nitrogen oxide $(\mathrm{NO})^{2}$ from (A) single pollutant covariate-adjusted linear regression ${ }^{3}$ models and (B) distributed lag covariate-adjusted linear regression ${ }^{3}$ among all participating children ( $n=423)$. ${ }^{1}$ IQR:NO2: 8.19 ppb; NO: 29.7 $\mathrm{ppb} .{ }^{2}$ Pollution levels used in regression models combine measured and imputed values. ${ }^{3}$ Covariates in each model: age, height, gender, race, school, caregiver smokes, caregiver's education, household income, phase, ashma severity, interactions between asthma severity and exposure. ${ }^{*} 5$ day average: average of lag1-lag5.

values ranging from 0.002 to 0.004 for $\mathrm{NO}_{2}$ and 0.003 to 0.012 for NO), compared with four in the north.

Results for associations between other air pollutants $\left(\mathrm{PM}_{10}\right.$, $\mathrm{SO}_{2}, \mathrm{CO}$ and $\mathrm{O}_{3}$ ) and lung function showed either no or few statistically significant relationships (online supplementary figures $\mathrm{S} 1-\mathrm{S} 3$ ).

The results from the DLM (figure $3 \mathrm{~B}$ ) were similar to the single exposure-single lag in terms of direction of effect, with a smaller exposure effect and less consistency of statistical significance. In the DLM, estimates for $\mathrm{NO}_{2}$ and $\mathrm{NO}$, ranged from 1 to $13 \mathrm{~mL}$ and 7 to $26 \mathrm{~mL}$ declines in $\mathrm{FEV}_{1}$, respectively, compared with the larger estimates from single-lag model reported above.

Generally, greater point estimates of decrements of lung function was associated with $\mathrm{NO}$ and $\mathrm{NO}_{2}$ among persistent asthmatics, compared with those without persistent asthma (figure 4B, online supplementary table S2). The north and south locations were also examined as effect modifiers. For both $\mathrm{NO}_{2}$ and $\mathrm{NO}$, point estimates for each of the four lagged models were lower in the south than in the north (figure 4C, online supplementary table S2). All eight models were statistically significant in the south ( $p$

\section{DISCUSSION}

Our findings showed a consistent pattern of acute lung function decrements with increasing exposure with $\mathrm{NO}_{\mathrm{x}}$ in this panel of schoolchildren. There was evidence to support a modification of this effect among those with AHR, persistent asthma and geographical location. Effects were present among those children without persistent asthma or AHR and varied across lags. 

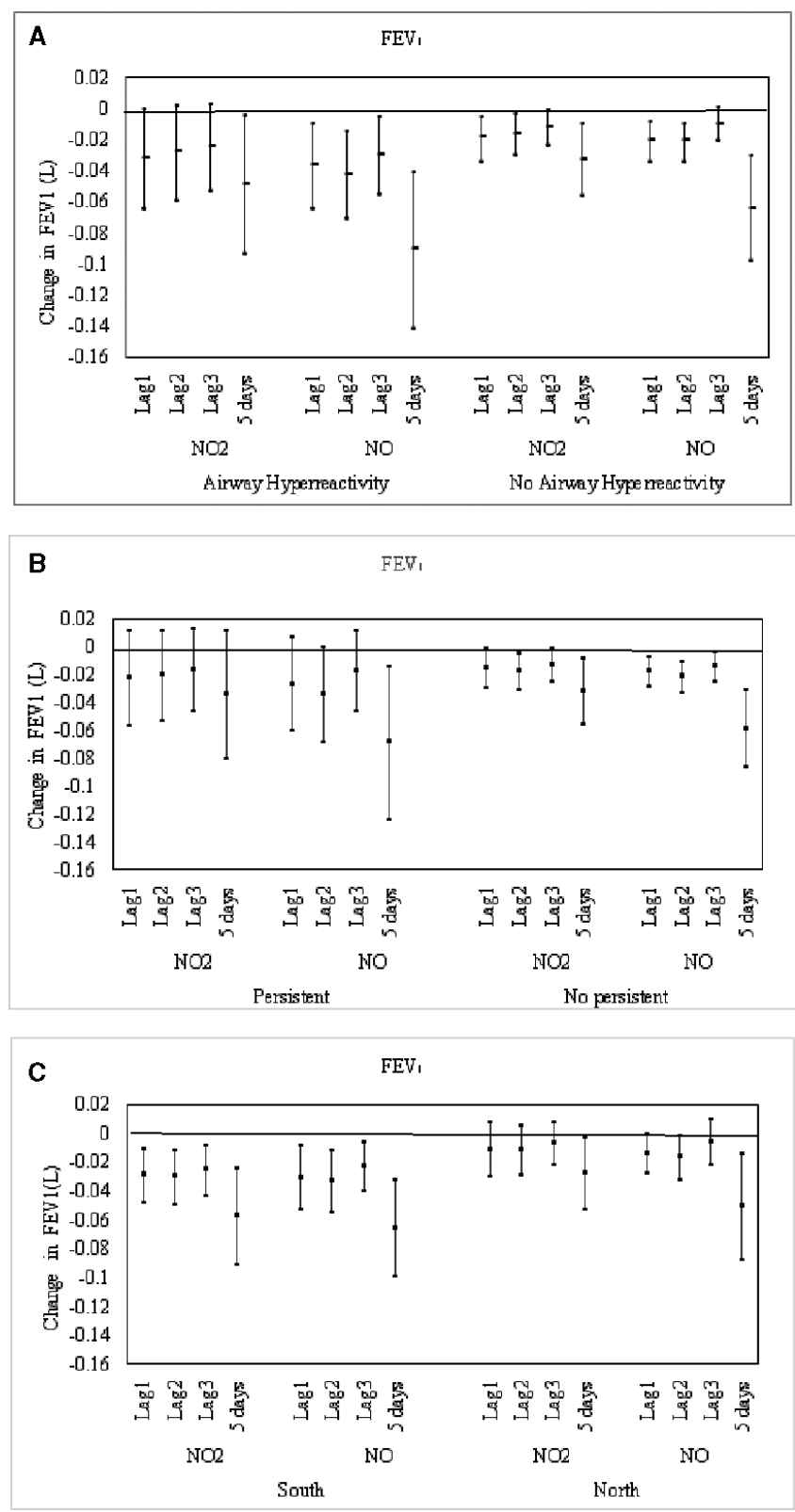

Figure 4 Change in $\mathrm{FEV}_{1}$ and its $95 \% \mathrm{Cl}$ associated with one $\mathrm{IQR}^{1}$ increase ambient levels of nitrogen dioxide $\left(\mathrm{NO}_{2}\right)^{2}$ and nitrogen oxide $(\mathrm{NO})^{2}$ from single pollutant linear regression ${ }^{3}$ models for (A) those with and without airway hyperresponsiveness; (B) those with and without persistent asthma and (C) those in the South and the North. ${ }^{1}$ IQR:NO2: $8.19 \mathrm{ppb}$; NO: $29.7 \mathrm{ppb} .{ }^{2}$ Pollution levels used in regression models combine measured and imputed values. ${ }^{3}$ Covariates in each model: age, height, gender, race, school, caregiver smokes, caregiver's education, household income, phase, ashma severity, interactions between asthma severity and exposure. *5 day average: average of lag1-lag5.

Our sample and design allowed for the investigation of several pollutants, varied exposure lags and both $\mathrm{FEV}_{1}$ and PEF outcomes. Despite the substantial power of our study (over 100 000 data points of interest), we were not able to show consistent associations with pollutants other than $\mathrm{NO}_{\mathrm{x}}$. This consistency and size of effect among all the participants in the panel is in keeping with findings from other studies.

Across several studies, $\mathrm{NO}_{2}$-related effects on cross-sectional assessments of $\mathrm{FEV}_{1}$ varied from $-3 \mathrm{~mL}$ through to $-49 \mathrm{~mL}$ per $10 \mu \mathrm{g} / \mathrm{m}^{3}$ increase in $\mathrm{NO}_{2}$, with a pooled estimate of $-8 \mathrm{~mL}$ per $10 \mu \mathrm{g} / \mathrm{m}^{3}$ increase in pollutant. ${ }^{26}$ The latter meta-analysis reported a drop of $14 \mathrm{~mL}$ among non-asthmatic children. While cross-sectional lung function measures may be a sensitive indicator among asthmatic children, this approach may be less so among non-asthmatics. The use of short-term measures, such as daily measures of lung function, compared against average pollutant exposure within the same timeframe may provide better insight into the pollutant-outcome relationship. Repeated measures within a panel study has several strengths. Apart from providing the opportunity to observe simultaneous time-series patterns in exposure and lung function measures, the short-term measures permit analysis of lagged effects of pollutant exposure, which is not possible in cross-sectional studies. With each participant serving as their own control, confounding of non-time varying factors are not influential in the assessment of the relationship between exposure and outcome. Notwithstanding this, we included non-time varying factors in the model, to potentially address study design issues.

In our panel, among those with persistent asthma, the reduction in $\mathrm{FEV}_{1}$ was almost $40 \mathrm{~mL}$ per IQR increase of $\mathrm{NO}_{2}$ and a statistically significant $70 \mathrm{~mL}$ per IQR increase for $\mathrm{NO}$ over the 5-day average exposure. Panel studies of asthmatic schoolchildren have reported changes in per cent predicted FEV ranging from 0.24 through to 1.41 over a 24 -hours lag. ${ }^{27}{ }^{28}$ In a meta-analysis of panel studies investigating the association between $\mathrm{NO}_{2}$ and PEF, the pooled estimate showed no decline in lung function, ${ }^{5}$ although statistically significant declines were reported in other studies. ${ }^{29-31}$ In a child panel study in Salamanca, Brazil, in which spirometric assessments were conducted in each of four seasons, no declines were observed for $\mathrm{NO}_{\mathrm{x}}$ but were seen for other pollutants. ${ }^{32}$

We previously reported a prevalence of $16.2 \%$ of marked or probable AHR and a further $10.6 \%$ with possible AHR in this sample. ${ }^{14}$ Reports of panel studies employing AHR as a measure are limited-we identified a single study which described greater ozone-related PEF declines in a panel of children among those with AHR compared with those without. ${ }^{33}$ Our findings showed a clear modification of the pollutant-related effect among those children with marked or probable AHR. Although the absolute difference in $\mathrm{FEV}_{1}$ across the AHR strata was small (ranging from about $20-30 \mathrm{~mL}$ ), this finding provides objective evidence that children with airways dysfunction are at greater risk for short-term pollutant exposure. A more surprising finding was that those children with possible or no AHR also showed a statistically significant pollutant-related effect across most lags. Our data clearly suggests that it is not only children with pre-existing disease that are affected by ambient pollution. However, whether these small decrements are likely the result of repeated airways insult during childhood and could translate into permanent airway damage in later life, provide interesting research questions for this population.

The modification by geographical location within the city was interesting, with pollutant-related effects being consistently greater in the south compared with the north, after adjusting for demographics and asthma severity. Our findings suggest that geographical location serves as a proxy for other unmeasured covariates. Similarly, our models including atopic status provided no clarity on this finding. One possible suggestion, based on our previous studies of this panel, may be a gene-pollutant interaction. We had previously reported that children in this sample, with the GSTP1 AG+GG genotype showed an increased risk for adverse outcomes with certain pollutants. ${ }^{34}$ The frequency of the GSTP1 AA genotype varied across geographical location (39.1\% in the south and $31.9 \%$ in the north). Although geographical 
differences have been described in other panel studies, these did not adjust for pollutant exposure at these locations. ${ }^{35} 36$ Our adjustment for likely covariates strongly suggests that other unmeasured factors, including possibly chemical variation of particulates, may explain these findings.

The pollutant-related mechanisms in inducing the lung function response is not well understood, and despite evidence for an acute outcome, there are inconsistencies in reported studies about the lag effect. We investigated several lags and a 5-day exposure average. For $\mathrm{NO}_{x}$, there were consistent effects in the expected direction across all lags and the 5-day average exposure. This consistency was absent for the other pollutants. Previous studies have reported 1-dayto 2-day lags among asthmatics, ${ }^{28}$ while others have observed no lag effects for $\mathrm{NO}_{x}{ }^{79}$ Other studies have reported effects for other pollutants such as ozone ${ }^{2437}$ and particulate matter. ${ }^{2428}$ These study-related inconsistencies in lagged effects are evident among both asthmatics and non-asthmatics and may therefore not be directly an airway-irritant effect. Reactive oxidative responses to $\mathrm{NO}_{\mathrm{x}} \mathrm{n}$ in the airways have been postulated to as the mechanism of airway reaction. ${ }^{38}$ These may cause airway damage over a period of time, leading to a more acute response following exposure. The challenge in population-based studies, unlike in controlled laboratory studies, is adjusting for the cumulative effect or prior day/s exposures on the airways. These are likely to have an effect in priming the airways for subsequent pollutant exposure but are not easily adjusted for sample selection, study design or statistical analysis. However, our $\mathrm{NO}_{\mathrm{x}}$-related responses in lung function, and its consistency with other studies provides further evidence that this pollutant is of particular concern within the broad suite of criteria pollutants, especially for acute outcomes.

The absence of a consistent pollutant-related effect with exposure to $\mathrm{PM}_{10}, \mathrm{SO}_{2}$ and $\mathrm{O}_{3}$ is contrary to the literature. ${ }^{242839}$ This may be explained either by exposure misclassification or because of our sample being a mixed asthma/non-asthma panel. Although we endeavoured to ensure that pupils lived in close proximity to the school, this was not always the case. In such events, it is likely that the school-based monitor did not adequately describe exposure for that particular child. Most of the previous studies which have reported effects have been on panels which included asthmatic children only.

The exposure contrasts, mix of pollutants and the large size of the panel recruited for the study, allowed for the analyses of effect modifications and pollutant interactions necessary to examine susceptible populations. The exposure assessments used in this study was based on data from monitoring stations located at each of the schools and regionally from the monitoring sites of the city's Air Quality Monitoring Network. Although there was missing data for certain time points, the availability of the extensive pollutant data set allowed us to develop models for data imputation. Although this imputation approach is likely to have added uncertainty to the exposure misclassification that may have occurred in our data, this was likely to have been at random. Our exposure measures were further compromised through the use of fixed monitors at schools, which did not account for at home exposures.

Although the levels of pollution in our study was below that of $\mathrm{WHO}$ guidelines, ${ }^{25}$ it was generally in the higher ranges of those reported in the literature from North American or European studies, with $\mathrm{PM}_{10}$ as much as twofold higher than that reported for Detroit $\left(26 \mu \mathrm{g} / \mathrm{m}^{3}\right)^{3}$ and NOx four fold higher as reported from Sweden $\left(17.3 \mu \mathrm{g} / \mathrm{m}^{3}\right) .{ }^{40}$ Our levels are comparable with studies from other developing countries such as Thailand and Korea. ${ }^{4142}$
A limitation in our study was the conduct of repeated lung function measures 'en masse'-all the children in the panel at all of the seven schools performed these assessments at more or less the same time, four times per schoolday, under the supervision of one field monitor in each class. Although pupils underwent training prior to each cycle, their correct technique cannot be guaranteed. Because of this, we used the technician performed spirometry data as the basis for determining the validity of bihourly measures. Those readings that were outside the $30 \%-120 \%$ range of the technician-derived $\mathrm{FEV}_{1}$ were rejected. Despite this, we still retained over 100000 lung function data points, which provided us with sufficient power to explore the health-pollutant relationship.

Because individuals are simultaneously exposed to many air pollutants, there is a need to consider the multipollutant exposure phenomenon. The presence of multicollinearity prevents the use of standard statistical methods. In addition, the potential for interaction between pollutants, the common measurement errors, the number of pollutants to include in models and the potential nonlinear relationship between exposure and health, make the multipollutant analysis almost impossible to conduct without biased point estimates, with large and unstable SE estimates and variance inflation. ${ }^{43} 44$

Single-exposure distributed lag models have been used to characterise the lag structure of exposure effects. These models assume that the coefficients corresponding to exposures at different lags follow a given known functional relationship and that a finite and known number of lags are included in a particular model. The single pollutant DLM can be extended to multipollutant scenarios with the same 'multicollinearity' caveat. ${ }^{45}$ The single-exposure single-lag model was the most efficient approach, given the limitations of the DLM, and because of our interest in the effect modification analyses. Nevertheless, we also modelled our data using the single-exposure DLMs as a 'validation' technique of the point estimates from the single-exposure single-lag models. Results from these two models were compared and showed some degree of consistency of point estimates and CIs.

These results are not surprising given the statistical assumptions of both models. On one hand, the single exposure single-lag models assume that all the effect of the exposure is concentrated in that particular lag; on the other, the distributed-lag models assume that there is known functional relationship among lags and that all the exposure effects are concentrated in the first five 24 hours daily averages.

To address clustering within child and child within location, we chose to use the GEE modelling, with the patterned compound symmetry structure. GEE estimates of model parameters are valid even if the covariance is mis-specified (because they depend on the first moment, eg, mean). Our approach to this was to use the empirical estimates with robust estimates of the SE.

In conclusion, our panel study of 423 schoolchildren showed statistically significant decline in lung function measured across a schoolday, in response to exposure to $\mathrm{NO}_{x}$, with effects significantly modified by AHR, persistent asthma and location. This effect was particularly consistent for $\mathrm{NO}$ and $\mathrm{NO}_{2}$ and less so for the other pollutants. Our study provides evidence of shortterm adverse responses in lung function following exposure to these pollutants at modestly high levels of exposure. Our findings indicate that current standards recommended by the WHO, particularly for $\mathrm{NO}_{x}$, are not protective of children with asthma. Further control of these exposures and improved regulation is necessary. The inconsistency in findings for the other pollutants suggest the need for further research. At a clinical management level, guardians of asthmatic children need to be aware of the 
increased risk of symptoms on high pollution days and subsequent days and days in which changing weather patterns may result in inversion layers.

Acknowledgements The authors are grateful for support given by the Pollution Control Unit of the eThekwini Department of Health and the Durban University of Technology. We express our appreciation to Yogan Gounden, Thabang Molefi, Pamela Nasirumbi, Mary Lou Thompson, Siva Chetty, and the staff and students of all the participating schools. We also thank the research fieldworkers and our research administrator Jenny Pillay.

Contributors RNN, SB and TR chiefly responsible for concept and design. RNN contributed to acquisition. GM chiefly responsible for analysis. Drafting the work was done primarily by GM and RNN, while SB and TR were involved in revising it critically for important intellectual content. All authors contributed to the interpretation of the data, final approval of the version published and agreed to be accountable for all aspects of the work in ensuring that questions related to the accuracy or integrity of any part of the work are appropriately investigated and resolved.

Funding This project was supported by grants from the eThekwini Municipality, the South African Medical Research Council, and the US National Institutes of Health/ Fogarty International Center (grant D43 TW000812). The funders played no role in the study design, collection, analysis or interpretation of the data, the writing of the reports or the decision to submit for publication.

Competing interests None declared.

Patient consent for publication Not required.

Ethics approval Ethical approval was obtained from the Institutional Review Board of the University of Michigan and the Biomedical Research Ethics Committee of the University of KwaZulu-Natal.

Provenance and peer review Not commissioned; externally peer reviewed.

Data availability statement No data are available.

ORCID iD

Rajen N Naidoo http://orcid.org/0000-0002-2318-4004

\section{REFERENCES}

1 Goldizen FC, Sly PD, Knibbs LD. Respiratory effects of air pollution on children. Pediatr Pulmonol 2016:51:94-108.

2 Zora JE, Sarnat SE, Raysoni AU, et al. Associations between urban air pollution and pediatric asthma control in El Paso, Texas. Sci Total Environ 2013:448:56-65.

3 Lewis TC, Robins TG, Mentz GB, et al. Air pollution and respiratory symptoms among children with asthma: vulnerability by corticosteroid use and residence area. Sci Total Environ 2013;448:48-55

4 Li S, Williams G, Jalaludin B, et al. Panel studies of air pollution on children's lung function and respiratory symptoms: a literature review. J Asthma 2012;49:895-910.

5 Weinmayr G, Romeo E, De Sario M, et al. Short-Term effects of PM10 and NO2 on respiratory health among children with asthma or asthma-like symptoms: a systematic review and meta-analysis. Environ Health Perspect 2010;118:449-57.

6 Gehring U, Gruzieva O, Agius RM, et al. Air pollution exposure and lung function in children: the escape project. Environ Health Perspect 2013;121:1357-64.

7 Smargiassi A, Goldberg MS, Wheeler AJ, et al. Associations between persona exposure to air pollutants and lung function tests and cardiovascular indices among children with asthma living near an industrial complex and petroleum refineries. Environ Res 2014;132:38-45.

8 Mölter A, Agius RM, de Vocht F, et al. Long-term Exposure to PM and NO in Association with Lung Volume and Airway Resistance in the MAAS Birth Cohort. Environ Health Perspect 2013;121:1232-8.

9 Amadeo B, Robert C, Rondeau V, et al. Impact of close-proximity air pollution on lung function in schoolchildren in the French West Indies. BMC Public Health 2015;15:45.

10 Ward DJ, Ayres JG. Particulate air pollution and panel studies in children: a systematic review. Occup Environ Med 2004;61:e13

11 Castro HA, Cunha MF, Mendonca GA, et al. Effect of air pollution on lung function in schoolchildren in Rio de Janeiro, Brazil. Rev Saude Publica 2009;43:26-34.

12 Matooane L, Diab RD. Air pollution carrying capacity in the South Durban industrial Basin. S Afr J Sci 2000;97:450-543.

13 Statistics South Africa. Poverty trends in South Africa. Report No. 03-10-06. Pretoria, 2017. Available: http://www.statssa.gov.za/publications/Report-03-10-06/Report-0310-062015.pdf [Accessed 28 Sep 2018].

14 Naidoo RN, Robins TG, Batterman S, et al. Ambient pollution and respiratory outcomes among schoolchildren in Durban, South Africa. S Afr J CH 2013;7:127-34.

15 Kistnasamy EJ, Robins TG, Naidoo R, et al. The relationship between asthma and ambient air pollutants among primary school students in Durban, South Africa. IJENVH 2008:2:365-85.
16 National Asthma Education and Prevention Program. Expert panel report: guidelines for the diagnosis and management of asthma. Bethesda, MD: National Institutes of Health, 1991.

17 American Thoracic Society. Standardization of spirometry - 1994 update. Am J Respir Crit Care Med 1995;152:1107-36.

18 American Thoracic Society. Guidelines for methacholine and exercise challenge Testing — 1999. Am J Respir Crit Care Med 2000;161:309-29.

19 eThekwini Health. Air quality management plan for eThekwini Municipality. produced by eThekwini health and Norwegian Institute for air research. Durban, 2007. Available: http://wwwsaagis.org.za/documents/ETHEKWINI\% 20METROPOLITAN\% 20MUNICIPALITY\%20AQMP.pdf [Accessed 30 Nov 2017].

20 Mentz G, Robins TG, Batterman S, et al. Acute respiratory symptoms associated with short term fluctuations in ambient pollutants among schoolchildren in Durban, South Africa. Environ Pollut 2018;233:529-39.

21 Teerenstra S, Lu B, Preisser JS, et al. Sample size considerations for Gee analyses of three-level cluster randomized trials. Biometrics 2010;66:1230-7.

22 Jung S-H, Ahn C. Sample size estimation for GEE method for comparing slopes in repeated measurements data. Stat Med 2003;22:1305-15.

23 Lake S, Kammann E, Klar N, et al. Sample size re-estimation in cluster randomization trials. Stat Med 2002;21:1337-50.

24 Lewis TC, Robins TG, Dvonch JT, et al. Air Pollution-Associated changes in lung function among asthmatic children in Detroit. Environ Health Perspect 2005;113:1068-75.

25 World Health Organisation,. Who air quality quidelines for particulate matter, ozone, nitrogen dioxide and sulfur dioxide. Geneva, Switzerland, 2005.

26 Barone-Adesi F, Dent JE, Dajnak D, et al. Long-Term exposure to primary traffic pollutants and lung function in children: cross-sectional study and meta-analysis. PLOS One 2015; 10:e0142565.

27 Dales R, Chen L, Frescura AM, et al. Acute effects of outdoor air pollution on forced expiratory volume in $1 \mathrm{~S}$ : a panel study of schoolchildren with asthma. Eur Respir J 2009;34:316-23.

28 Delfino RJ, Staimer N, Tjoa T, et al. Personal and ambient air pollution exposures and lung function decrements in children with asthma. Environ Health Perspect 2008; 116:550-8

29 Kalandidi A, Gratziou C, Katsouyanni K, et al. Air pollution and respiratory health of children: the peace panel study in Athens, Greece. Eur Respir Rev 1998;8:117-24.

30 Rudnai P, Vaskövi E, Paldy A, et al. Air pollution and respiratory health of children: the peace panel study in Hungary. Eur Respir Rev 1998;8:101-7.

31 Kotesovec F, Vitnerova N, Leixner M, et al. Air pollution and respiratory health of children: the peace panel study in Teplice, Czech Republic. Eur Respir Rev 1998:8:70-7.

32 Linares B, Gulzar JM, Armador N, et al. Impact of air pollution on pulmonary function and respiratory symptoms in children. longitudinal repeated-measures study. BMC Pulm Med 2010;24

33 Jalaludin BB, Chey T, O'Toole BI, et al. Acute effects of low levels of ambient ozone on peak expiratory flow rate in a cohort of Australian children. Int J Epidemiol 2000;29:549-57.

34 Reddy P, Naidoo RN, Robins TG, et al. GSTM1 and GSTP1 gene variants and the effect of air pollutants on lung function measures in South African children. Am J Ind Med 2012;55:1078-86.

35 Ranzi A, Freni Sterrantino A, Forastiere F, et al. Asthmatic symptoms and air pollution: a panel study on children living in the Italian PO Valley. Geospat Health 2015;10:366.

36 Sarnat SE, Raysoni AU, Li W-W, et al. Air pollution and acute respiratory response in a panel of asthmatic children along the U.S.-Mexico border. Environ Health Perspect 2012:120:437-44

37 Schachter EN, Moshier E, Habre R, et al. Outdoor air pollution and health effects in urban children with moderate to severe asthma. Air Qual Atmos Health 2016;9:251-63.

38 Persinger RL, Poynter ME, CKless $\mathrm{K}$, et al. Molecular mechanisms of nitrogen dioxide induced epithelial injury in the lung. Mol Cell Biochem 2002;235:71-80.

39 Trenga CA, Sullivan JH, Schildcrout JS, et al. Effect of particulate air pollution on lung function in adult and pediatric subjects in a Seattle panel study. Chest 2006;129:1614-22.

40 Lindgren A, Stroh E, Björk J, et al. Asthma incidence in children growing up close to traffic: a registry-based birth cohort. Environ Health 2013;12.

41 Vichit-Vadakan N, Ostro BD, Chestnut LG, et al. Air pollution and respiratory symptoms: results from three panel studies in Bangkok, Thailand. Environ Health Perspect 2001;109(Suppl 3):381-7.

42 Lee BE, EH H, Park HS, et al. Air pollution and respiratory symptoms of school children in a panel study in Seoull. J Prev Med Public Health 2005;38:465-72.

43 Zanobetti A, Austin E, Coull BA, et al. Health effects of multi-pollutant profiles. Environ Int 2014;71:13-19.

44 Pearce JL, Waller LA, Mulholland JA, et al. Exploring associations between multipollutant day types and asthma morbidity: epidemiologic applications of selforganizing map ambient air quality classifications. Environ Health 2015;14.

45 Chen YH, Mukherjee B, Adar SD, et al. Robust distributed lag models using data adaptive shrinkage. Biostatistics 2017 